\title{
Reproductive hormone profile and pubertal development in 14-year-old boys prenatally exposed to polychlorinated biphenyls
}

\section{Citation}

Grandjean, Philippe, Ciea Grønlund, Ina M. Kjær, Tina Kold Jensen, Nicolina Sørensen, AnnaMaria Andersson, Anders Juul, Niels E. Skakkebæk, Esben Budtz-Jørgensen, and Pal Weihe. 2012. "Reproductive Hormone Profile and Pubertal Development in 14-Year-Old Boys Prenatally Exposed to Polychlorinated Biphenyls." Reproductive Toxicology 34 (4) (December): 498-503. doi:10.1016/j.reprotox.2012.07.005.

\section{Published Version}

doi:10.1016/j.reprotox.2012.07.005

\section{Permanent link}

http://nrs.harvard.edu/urn-3:HUL.InstRepos:34767894

\section{Terms of Use}

This article was downloaded from Harvard University's DASH repository, and is made available under the terms and conditions applicable to Other Posted Material, as set forth at http:// nrs.harvard.edu/urn-3:HUL.InstRepos:dash.current.terms-of-use\#LAA

\section{Share Your Story}

The Harvard community has made this article openly available.

Please share how this access benefits you. Submit a story.

Accessibility 


\title{
Reproductive hormone profile and pubertal development in 14- year-old boys prenatally exposed to polychlorinated biphenyls
}

\author{
Philippe Grandjean a,b, ${ }^{,}$, Ciea Grønlund ${ }^{\mathrm{a}}$, Ina M Kjæra ${ }^{\mathrm{a}}$, Tina Kold Jensen ${ }^{\mathrm{a}}$, Nicolina \\ Sørensen $^{c}$, Anna-Maria Andersson ${ }^{d}$, Anders Juul ${ }^{d}$, Niels E Skakkebæk ${ }^{d}$, Esben Budtz- \\ Jørgensen ${ }^{\mathrm{e}}$, and Pal Weihe ${ }^{\mathrm{C}}$
}

Philippe Grandjean: pgrand@sdu.dk; Ciea Grønlund: ciea.groenlund@gmail.com; Ina M Kjær: inamathildekjaer@gmail.com; Tina Kold Jensen: tkjensen@health.sdu.dk; Nicolina Sørensen: nicolina@dadlnet.dk; AnnaMaria Andersson: anna@rh.dk; Anders Juul: anders.juul@rh.regionh.dk; Niels E Skakkebæk:

niels.erik.skakkebaek@rh.regionh.dk; Esben Budtz-Jørgensen: ebj@sund.ku.dk; Pal Weihe: pal@health.fo

aDepartment of Environmental Medicine, University of Southern Denmark, 5000 Odense, Denmark bepartment of Environmental Health, Harvard School of Public Health, Boston, MA 02215, United States ${ }^{\mathrm{C}}$ Faroese Hospital System, FR-100 Tórshavn, Faroe Islands dDepartment of Growth and Reproduction, Rigshospitalet, Faculty of Health Sciences, University of Copenhagen, 2100 Copenhagen, Denmark ${ }^{\mathrm{e}}$ Department of Biostatistics, University of Copenhagen, DK-2100 Copenhagen, Denmark

\begin{abstract}
Because polychlorinated biphenyls (PCBs) are thought to cause endocrine disruption, we examined 438 adolescent boys from a birth cohort in the Faroe Islands, where PCB exposures are elevated. We measured PCBs and $p, p^{\prime}$-dichlorodiphenyldichloroethylene (DDE) in cord blood and in serum from clinical examination at age 14. Higher prenatal PCB exposure was associated with lower serum concentrations of both luteinizing hormone ( $\mathrm{LH})$ and testosterone. In addition, sex hormone binding globulin (SHBG) was positively associated with both prenatal and concurrent PCB exposures. The PCB-SHBG association was robust to covariate adjustment. In a structural equation model, a doubling in prenatal PCB exposure was associated with a decrease in $\mathrm{LH}$ of $6 \%$ $(\mathrm{p}=0.03)$. Prenatal exposure to PCB and DDE showed weak, non-significant inverse associations with testicular size and Tanner stage. DDE was highly correlated with PCB and showed slightly weaker associations with the hormone profile. These findings suggest that delayed puberty with low serum-LH concentrations associated with developmental exposure to non dioxin-like PCBs may be due to a central hypothalamo-pituitary mechanism.
\end{abstract}

\section{Keywords}

Adolescent development; Delayed puberty; Polychlorinated biphenyls; Prenatal exposure delayed effects; Reproductive hormones

() 2012 Elsevier Inc. All rights reserved.

"Corresponding author at: Department of Environmental Health, Harvard School of Public Health, 401 Park Drive, 3E-110, Boston, MA 02215, USA. Tel.: +1 617384 8907; fax: +1 6173848994

Conflicts of interest

The authors declare they have no conflicts of interest.

Publisher's Disclaimer: This is a PDF file of an unedited manuscript that has been accepted for publication. As a service to our customers we are providing this early version of the manuscript. The manuscript will undergo copyediting, typesetting, and review of the resulting proof before it is published in its final citable form. Please note that during the production process errors may be discovered which could affect the content, and all legal disclaimers that apply to the journal pertain. 


\section{Introduction}

Developmental exposure to polychlorinated biphenyls (PCBs) and related persistent pollutants may cause testicular dysfunction in humans [1]. PCB congeners are known to cause both neurotoxicity [2,3] and endocrine disruption [4], the latter supported by experimental demonstration of adverse effects on both testicular cells [5] and the hypothalamus [6,7]. Thus, PCBs may potentially exert adverse effects by affecting different aspects of the hypothalamic-pituitary-gonadal axis [4, 7]. Among adverse outcomes, PCB has been linked to decreases in serum concentrations of testosterone and other hormones, and in reduced fertility and hormone-sensitive cancers $[4,8,9]$.

Human PCB exposure also involves other persistent and lipophilic chemicals, such as $p, p^{\prime}-$ dichlorodiphenyltrichloroethane (DDT) and its more persistent metabolite $p, p^{\prime}-$ dichlorodiphenyldichloroethylene (DDE), both of which have also been implicated as endocrine disruptors $[4,10]$. Epidemiological studies may address the joint effect of contaminant exposures, but linkage of adverse effects to specific exposures depends on the extent of collinearity between the contaminants.

Susceptibility to endocrine disruption is likely to be the greatest when exposures happen prenatally [11]. However, most epidemiological studies in this field are cross-sectional and have examined the serum concentrations of PCBs and DDE at the same time as the clinical assessment of testicular function $[12,13]$. As the current serum concentration may not reflect the causative exposure, which may have occurred decades ago during sensitive stages of early development, such evidence cannot confirm or refute a hypothesis of endocrine dysfunction.

The aim of the present study is to examine the association between prenatal exposures to PCB and DDE and puberty development outcomes, including the reproductive hormone profile. We chose to carry out this study in the Faroe Islands, where exposures to PCBs and DDE are increased due to the traditional habit of eating pilot whale blubber [2]. Being at the top of marine food chains, pilot whales accumulate persistent lipophilic contaminants, especially PCBs and DDE [14]. We initiated a Faroese birth cohort in 1986-1987 and carried out clinical follow-up at puberty age $[2,15,16]$. In our initial studies, lipophilic contaminants were measured in cord tissue, but we have now determined the concentrations in cord blood [17].

\section{Material and methods}

\subsection{Cohort subjects}

The Faroese birth cohort was collected consecutively at the three Faroese hospitals over a 21 month period 1986-1987 [18]. In total, 75\% of all births in this period are included in the cohort. The midwife collected a blood sample from the umbilical cord from almost all cohort members. Cord blood was frozen and has now been analyzed for major PCB congeners and DDE. At age 14 years, a total of 438 boys (out of 501 eligible members of the original birth cohort) participated in clinical examinations carried out during two threemonth periods (i.e. twice a 3 -month period) over a 15-month period. Following the clinical examination, a venous blood sample was obtained, i.e., either at noon or 5 p.m. Serum was isolated, and frozen at $-70^{\circ} \mathrm{C}$ until analyses of reproductive hormones in Copenhagen [16]. Sufficient serum volume to allow hormone analyses was available for 402 subjects.

Clinical examinations were carried out by two pediatricians. Puberty development was determined by Tanner stages for pubic hair (P1-P5) and genital development (G1-G5) [19]. Testicular volume in $\mathrm{mL}$ was assessed by use of an orchidometer [20], and, in a subgroup 
examined by one of the pediatricians, by ultrasound measurement. Height and body weight were used to calculate the body mass index (BMI).

The protocol included written informed consent and was approved by the ethical review committee of the Faroe Islands and by the institutional review board at the U.S. Institution.

\subsection{Exposure assessment}

Developmental exposure levels were determined from analysis of banked whole blood taken from the umbilical cord from all birth cohort members [17]. Major PCB congeners and related compounds were measured by gas chromatography with electron capture detection. The total PCB exposure was estimated as twice the sum of serum concentrations of the most prevalent PCB congeners 138, 153 and 180 [21]. This approximation is used because it avoids problems with congener concentrations below the detection limit, and because previous studies of the same cohort have shown that these three PCB congeners represent about 50\% of the total concentration of PCBs. Cord blood PCB concentrations were expressed on a volume basis, as lipid analysis was not carried out. An average lipid concentration of $3 \mathrm{~g} / \mathrm{L}$ in cord blood can be used for lipid adjustment of volume-based concentrations. Concentrations of PCB congeners in cord serum correlate well with those in milk and maternal serum, but lipid-based concentrations in cord serum average about $60 \%$ of those in the maternal circulation [22].

In addition, serum obtained at the clinical examination at age 14 years was also analyzed for PCBs and DDE, and lipid-based concentrations were calculated as previously described [16].

\subsection{Analysis of reproductive hormones}

Serum FSH and LH were measured by time-resolved immunofluorometric assays (Delfia; PerkinElmer, MA, USA) with detection limits of 0.06 and 0.05 IU/L, respectively. Intra- and interassay coefficient of variation (CV) were less than $5 \%$ in both gonadotropin assays. Testosterone (T) was measured with the Coat-A-Count RIA kit (Siemens Healthcare Diagnostics, CA, USA). The detection limit was $0.23 \mathrm{nmol} / \mathrm{L}$ and the intra- and interassay $\mathrm{CV}$ were below $8 \%$ and $9 \%$, respectively. SHBG was measured by time-resolved immunofluorometric assay (Delfia; PerkinElmer, MA, USA) with a detection limit of 0.23 $\mathrm{nmol} / \mathrm{L}$, and intra- and inter-assay CVs were less than 5.1\%. Inhibin B was determined using a specific two-sided enzyme immunometric assay from Oxford Bio-Innovation Ltd. (Oxford, UK). The sensitivity of the inhibin B assay was $20 \mathrm{pg} / \mathrm{mL}$, and the intra- and interassay CVs were less than $12 \%$ and less than $17 \%$, respectively. For the results below the detection limit (mainly T), we assumed that the result was the detection limit divided by square root 2 . All assays were validated in the analytical laboratory as previously described $[23,24]$.

\subsection{Statistical analysis}

Both PCB and DDE concentrations showed a skewed Gaussian distribution, and tertile groups were therefore formed. Logarithmic transformation of both exposure biomarkers and of all hormone parameters, except for inhibin B was needed to approach a Gaussian distribution of residuals to allow use of parametric methods. Correlation coefficients were calculated as a first step, supplemented by partial coefficients. Multiple regression analysis was then carried out both before and after adjustment for age, BMI, time of blood sample (hormone concentrations), and examiner (testicular size and Tanner stage) and as potential confounders selected a priori. In regard to testicular size, subjects with a history of cryptorchidism $(\mathrm{N}=28)$ were excluded. While Tanner stage in our previous study had shown no association with the cord-tissue PCB concentration [16], adjustment for Tanner 
stage was considered in sensitivity analyses. We assessed associations both with the prenatal and the concurrent PCB and DDE exposures. Generalized additive models were used to estimate the possible linearity of the associations [25].

To explore the combined effect on the hormone profile, we used a structural equation model $[26,27]$. In this factor analysis approach, the outcome variables are considered as reflections of the same latent variable representing the true endocrine disruption. The exposure biomarkers are then considered as predictors of changes in the latent variable, as affected by the covariates. The exposure parameters can also be combined into a latent exposure variable. We have previously used this methodology [28-30], as information from multiple exposures and multiple outcomes can be included simultaneously. This approach affords greater statistical power and avoids the need for adjustment for multiple comparisons [30]. The appropriateness of the model fit was confirmed by comparing the expected and the observed covariance in a $\chi^{2}$ test.

\section{Results}

Table 1 shows the main characteristics of the participants. The correlation coefficients between $\log$ transformed concentrations in cord blood and adolescent serum were 0.40 for PCB and 0.35 for DDE. PCB and DDE were highly correlated between the two sampling occasions ( $r=0.89$ for cord blood and $r=0.79$ for age- 14 serum). Prenatal exposure to PCB and DDE did not differ between subjects with and without a history of cryptorchidism.

Despite similarity in age, the boys showed much variability in regard to body proportions and puberty development. Testicular size was measured in most boys $(\mathrm{N}=327)$ by orchidometer. Ultrasound assessments of testicular volumes in 107 boys correlated well with orchidometry results $(\mathrm{r}=0.90)$, which averaged $29 \%$ greater in the 60 boys with both measures. Despite the narrow age range, testicular size was significantly associated with age $(r=0.20 ; p<0.001)$. Prenatal PCB exposure showed a weak inverse association with testicular size $(\mathrm{r}=-0.08 ; \mathrm{p}=0.14$ after adjustment for age and examiner and exclusion of subjects with history of cryptorchidism). The correlation with cord-blood DDE was similar $(r=-0.11 ; p=0.07)$, while no such tendency was seen for the age-14 serum PCB and DDE concentrations. When including adjusted ultrasound measures, testicular size was available for 374 boys; associations were similar for these extended data. Regression analysis for testicular size showed a decrease by $1.14 \mathrm{~mL}$ for a 10-fold increase both in PCB $(p=0.14)$ and DDE $(\mathrm{p}=0.07)$ after adjustment for age and examiner and exclusion of subjects with a history of cryptorchidism.

Tanner stage was determined in 394 boys. The ten boys who had reached pubic stage 5 had a geometric mean cord blood PCB concentration of $1.25 \mu \mathrm{g} / \mathrm{L}$, as compared to the average among all other boys of $1.95 \mu \mathrm{g} / \mathrm{L}(\mathrm{p}=0.07)$. Although exposures at stages $2-4$ were fairly similar and not significantly different, the overall inverse trend reached statistical significance $(r=-0.14 ; p=0.014)$ for non-cryptorchid boys after controlling for age and examiner, with the same result for DDE and for Tanner stage for genital development. However, neither Tanner stage was associated with the concurrent concentrations of PCB or DDE.

The reproductive hormone concentrations showed much variability, but all of them were strongly associated with Tanner stages, $\mathrm{T}$ most strongly with the pubic hair stage $(\mathrm{r}=0.73 ; \mathrm{p}$ $<0.001)$. The results were compared with the prenatal PCB exposure in tertile groups, i.e., with the lowest tertile below $1.45 \mu \mathrm{g} / \mathrm{L}$ and the highest above $2.72 \mu \mathrm{g} / \mathrm{L}$ (Table 2). Although of borderline significance, LH, T, and SHBG showed exposure-associated differences between the tertile groups, whereas no such tendency was seen for FSH and inhibin-B. Exclusion of subjects with a history of cryptorchidism only marginally affected these results. 
Generalized additive models for PCB-associated changes in serum hormone concentrations (Fig. 1) suggest that the relationships did not deviate substantially from linear.

Regression analysis was carried out with LH, T, and SHGB as dependent variables (Table 3 ). Adjustment for covariates changed the regression coefficients only marginally. The free fraction of $\mathrm{T}$, as expressed by the T/SHBG ratio (log transformed) showed the largest relative change associated with prenatal $\mathrm{PCB}$ exposure, in agreement with the results for $\mathrm{T}$ and SHBG. After additional adjustment of hormone concentrations for Tanner stage, all beta values decreased numerically, the result only for SHBG remaining statistically significant (beta $=0.06 ; \mathrm{p}=0.03$ ). As hormone concentrations were $\log$ transformed, the largest beta value ( -0.245 for the T/SHBG ratio) suggests a decrease by about $43 \%$ at a 10 -fold increase in the PCB concentration, or about $16 \%$ for each doubling in PCB exposure.

The concurrent PCB concentration was associated only with the SHBG concentration $(r=$ $0.19 ; \mathrm{p}<0.001)$. After adjustment for covariates, including BMI and Tanner stage, the regression coefficient for PCB as a predictor of SHBG remained statistically significant (beta $=0.080 ; p=0.003$ ). As both variables were log transformed, this value corresponds to an increase in SHBG by about 6\% for each doubling in the concurrent PCB exposure.

We also conducted regression analyses using the results for individual PCB congeners and for DDE in cord blood. The results were similar to those obtained for the total PCB concentration, and the associations could therefore not be reliably attributed to any particular analyte. A small number of outliers were observed, but exclusion of these observations did not materially change the results described above.

Structural equation analysis confirmed the tendency shown by the individual outcome variables, and the model including T, SHBG and LH fit the data well (with the effect on SHBG being in the opposite direction compared to the two others) (Table 3). When expressed in terms of percent change in the latent variable on the LH scale, a 10-fold increase in PCB resulted in a decrease of $18.5 \%$ (95\% CI, 1.9; 32.0). For a doubling in exposure, the decrease in LH was approximately $6 \%$. When DDE was used as the exposure parameter, the effect was slightly less than for PCB. When both PCB and DDE were included in the same latent exposure variable, the association with the outcome variable was weaker than for PCB alone.

\section{Discussion}

The present study is unique, as it constitutes a prospective follow-up of consecutive births in a fishing community with a substantial range of exposures to persistent lipophilic pollutants. Increased prenatal exposures determined from cord blood concentrations of PCBs and DDE were associated with slightly delayed puberty in the boys and an altered profile of serum concentrations of reproductive hormones at clinical follow-up at age 14 years. Due to the scheduling of clinical examinations during two three-month periods, the boys were approximately the same age when examined, though in different stages of pubertal development. The variability in development allowed assessment of possible PCBassociated effects on puberty stage and hormone profile. While the correlations between exposure and hormone data were attenuated after adjustment for Tanner stage, such adjustment for a clinical parameter that is part of the same causal chain does not invalidate the findings, but supports a potential causal linkage between the outcomes.

The lower serum concentrations of T and LH, and the higher SHBG suggest that endocrine disruption due to developmental PCB exposure could be mediated via toxicity to the central part of the hypothalamo-pituitary-gonadal axis, perhaps linked to central nervous system toxicity, as demonstrated in experimental studies [6,7]. This mode of developmental 
programming leading to delayed puberty would be in accordance with the lower concentrations of both LH and T and higher SHBG. These associations differ from dioxinmediated effects that primarily result in a decreased serum-inhibin B concentration, associated with an increase in FSH, thus clearly suggesting peripheral dysfunction of the Sertoli cells [31]. In our study, inhibin B and FSH concentrations were not associated with the PCB and DDE exposures. The associations observed in this study therefore cannot be attributed to dioxin-related mechanisms. Whether or not any central PCB-mediated effects persist into adult life remains to be seen.

The PCB-associated increase in SHBG showed a different pattern than other endocrine parameters assessed, as SHBG alone was associated also with the current PCB exposure. As also observed in the present study, this parameter decreases with the progress of puberty [32], but it is influenced by multiple other factors, such as IGF-I, thyroid hormones and insulin [33]. Still, the positive association between PCB and SHBG remained after adjustment for covariates, even including Tanner stage. Positive associations with PCB exposure have also been reported in cross-sectional studies of adult men $[8,34,35]$. PCBs are known to affect a variety of liver functions [36], and PCB-induced hepatic SHBG synthesis could therefore play a possible role, although this possibility remains to be substantiated.

The PCB exposures in the Faroes are elevated in comparison with other birth cohorts [37] due to the traditional habit of eating pilot whale blubber. As PCB and DDE exposures originate from the same source, the high collinearity between their serum concentrations, and between PCB congeners amongst themselves [17] is not surprising. However, the close correlation between exposure parameters precludes any conclusion in regard to the specific causality or mechanism underlying the correlations observed. Due to the weaker DDE associations with the hormone concentrations, this contaminant would be unlikely to account for the PCB-related changes in this study. Even dioxin-like PCB congeners showed associations with the outcomes that were similar to those reflected by the total PCB concentration. However, dioxin exposures as such are not elevated in the Faroes [21].

We previously reported that the occurrence of spermaturia in 58 out of 176 boys from the same cohort was not associated with the PCB concentration in the umbilical cord tissue, but that spermaturia was associated with Tanner stage and testicular size [16]. Boys with spermaturia had increased serum concentrations of T and LH, while SHBG was lower than in boys without spermaturia [16]. In concert with these observations, the present study suggests that developmental PCB exposure may not have a direct effect on Sertoli cells and spermatogenesis, which may be more sensitive to developmental dioxin exposure [31].

Few other studies have evaluated prenatal contaminant exposures and pubertal outcomes. Developmental exposure to PCBs at lower levels seems not to affect pubertal timing in boys [38], although reduced penile length has been reported at high levels of exposure [39]. However, we are not aware of other studies on adolescent reproductive hormone concentration associated with prenatal PCB exposure.

Support of the present findings is available from experimental studies. Thus, in vitro exposure of human fetal penile cells to highly persistent PCB congeners caused downregulation of genes involved both in $\mathrm{LH}$ and testosterone production [40]. In adult male rats, PCB exposure caused a decreased density of Leydig cell LH receptors and a lower $17 \beta$ hydroxysteroid dehydrogenase expression, thereby leading to a decreased LH-stimulated $\mathrm{T}$ production [5]. In female rats developmentally exposed to PCBs, abnormalities in serum-LH concentrations were found, even in the F2 generation [41]. In female lambs developmentally exposed to PCB-118 or PCB-153, an increased LH secretion was observed in response to 
administration of gonadotropin releasing hormone [42]. This observation suggests that decreases in both $\mathrm{T}$ and $\mathrm{LH}$, as seen in our study, could be due to a central deficit.

Neurotoxicity associated with developmental PCB exposure has been well documented [2, $3]$, although the mechanisms affecting gonadotropin releasing hormone release are poorly known.

At this point, the long-term implications of our results are difficult to predict, as the cohort members at the time of examination were only in mid-puberty. However, the endocrine dysfunction observed in this study could possibly lead to deficits in male reproductive development and secondary sex characteristics. The average PCB exposure in the Faroes is elevated, and the wide range of exposures provided statistical power to detect relatively small changes. Future studies should aim at further specifying the dose dependence and differences between effects associated with dioxin-like compounds and PCBs that are not dioxin-like.

\section{Conclusions}

In adolescent boys with increased prenatal exposure to non dioxin-like PCBs, the cord blood PCB concentration was inversely associated with serum concentrations of T and LH at age 14 years. Weak, non-significant inverse associations with testicular size and Tanner stage were also seen. These findings from a prospective birth cohort study suggest that endocrine disruption associated with developmental exposure to non dioxin-like PCBs may be due to a central mechanism, perhaps linked to neurotoxicity. The possible persistence of such effects may be determined by further follow-up of the cohort into adulthood.

\section{Acknowledgments}

This research was supported by the U.S. National Institute of Environmental Health Sciences (ES09797). The contents of this paper are solely the responsibility of the authors and do not necessarily represent the official views of the NIEHS, NIH or any other funding agency.

\section{Abbreviations}

$\begin{array}{ll}\text { CV } & \text { coefficient of variation } \\ \text { DDE } & \text { dichlorodiphenyldichloroethylene } \\ \text { DDT } & \text { dichlorodiphenyltrichloroethane } \\ \text { LH } & \text { luteinizing hormone } \\ \text { PCB } & \text { polychlorinated biphenyl } \\ \text { SHBG } & \text { sex hormone binding globulin } \\ \text { T } & \text { testosterone }\end{array}$

\section{References}

1. Cao Y, Winneke G, Wilhelm M, Wittsiepe J, Lemm F, Furst P, et al. Environmental exposure to dioxins and polychlorinated biphenyls reduce levels of gonadal hormones in newborns: results from the Duisburg cohort study. Int J Hyg Environ Health. 2008; 211:30-9. [PubMed: 17660003]

2. Grandjean P, Weihe P, Burse VW, Needham LL, Storr-Hansen E, Heinzow B, et al. Neurobehavioral deficits associated with PCB in 7-year-old children prenatally exposed to seafood neurotoxicants. Neurotoxicology and teratology. 2001; 23:305-17. [PubMed: 11485834] 
3. Boucher O, Muckle G, Bastien CH. Prenatal exposure to polychlorinated biphenyls: a neuropsychologic analysis. Environmental health perspectives. 2009; 117:7-16. [PubMed: 19165381]

4. Diamanti-Kandarakis E, Bourguignon JP, Giudice LC, Hauser R, Prins GS, Soto AM, et al. Endocrine-disrupting chemicals: an Endocrine Society scientific statement. Endocr Rev. 2009; 30:293-342. [PubMed: 19502515]

5. Murugesan P, Kanagaraj P, Yuvaraj S, Balasubramanian K, Aruldhas MM, Arunakaran J. The inhibitory effects of polychlorinated biphenyl Aroclor 1254 on Leydig cell LH receptors, steroidogenic enzymes and antioxidant enzymes in adult rats. Reprod Toxicol. 2005; 20:117-26. [PubMed: 15808795]

6. Parent AS, Naveau E, Gerard A, Bourguignon JP, Westbrook GL. Early developmental actions of endocrine disruptors on the hypothalamus, hippocampus, and cerebral cortex. J Toxicol Environ Health B Crit Rev. 2011; 14:328-45. [PubMed: 21790315]

7. Dickerson SM, Cunningham SL, Gore AC. Prenatal PCBs disrupt early neuroendocrine development of the rat hypothalamus. Toxicol Appl Pharmacol. 2011; 252:36-46. [PubMed: 21277884]

8. Meeker JD, Hauser R. Exposure to polychlorinated biphenyls (PCBs) and male reproduction. Syst Biol Reprod Med. 2010; 56:122-31. [PubMed: 20377311]

9. McGlynn KA, Quraishi SM, Graubard BI, Weber JP, Rubertone MV, Erickson RL. Persistent organochlorine pesticides and risk of testicular germ cell tumors. J Natl Cancer Inst. 2008; 100:66371. [PubMed: 18445826]

10. Audouze K, Grandjean P. Application of computational systems biology to explore environmental toxicity hazards. Environmental health perspectives. 2011

11. Grandjean P, Bellinger D, Bergman A, Cordier S, Davey-Smith G, Eskenazi B, et al. The Faroes statement: human health effects of developmental exposure to chemicals in our environment. Basic Clin Pharmacol Toxicol. 2008; 102:73-5. [PubMed: 18226057]

12. Bonde JP, Toft G, Rylander L, Rignell-Hydbom A, Giwercman A, Spano M, et al. Fertility and markers of male reproductive function in Inuit and European populations spanning large contrasts in blood levels of persistent organochlorines. Environmental health perspectives. 2008; 116:269_ 77. [PubMed: 18335090]

13. Goncharov A, Rej R, Negoita S, Schymura M, Santiago-Rivera A, Morse G, et al. Lower serum testosterone associated with elevated polychlorinated biphenyl concentrations in Native American men. Environmental health perspectives. 2009; 117:1454-60. [PubMed: 19750113]

14. Borrell, A.; Aguilar, A. Pollution by DDT and PCB in blubber and muscle of long-finned pilot whales from the Faroe Islands. In: Donovan, GP.; Lockyer, CH.; Martin, AR., editors. Biology of northern hemisphere pilot whales. Cambridge: International Whaling Commission; 1993. p. 351-67.

15. Debes F, Budtz-Jorgensen E, Weihe P, White RF, Grandjean P. Impact of prenatal methylmercury exposure on neurobehavioral function at age 14 years. Neurotoxicol Teratol. 2006; 28:363-75. [PubMed: 16647838]

16. Mol NM, Sorensen N, Weihe P, Andersson AM, Jorgensen N, Skakkebaek NE, et al. Spermaturia and serum hormone concentrations at the age of puberty in boys prenatally exposed to polychlorinated biphenyls. Eur J Endocrinol. 2002; 146:357-63. [PubMed: 11888842]

17. Grandjean P, Weihe P, Nielsen F, Heinzow B, Debes F, Budtz-Jørgensen E. Neurobehavioral deficits at age 7 years associated with prenatal exposure to toxicants from maternal seafood diet. Neurotoxicol Teratol. 2012 Jul; 34(4):466-72. [PubMed: 22705177]

18. Grandjean P, Weihe P, Jorgensen PJ, Clarkson T, Cernichiari E, Videro T. Impact of maternal seafood diet on fetal exposure to mercury, selenium, and lead. Archives of Environmental Health. 1992; 47:185-95. [PubMed: 1596101]

19. Marshall WA, Tanner JM. Variations in the pattern of pubertal changes in boys. Arch Dis Child. 1970; 45:13-23. [PubMed: 5440182]

20. Zachmann M, Prader A, Kind HP, Hafliger H, Budliger H. Testicular volume during adolescence. Cross-sectional and longitudinal studies. Helv Paediatr Acta. 1974; 29:61-72. [PubMed: 4838166] 
21. Grandjean P, Weihe P, Needham LL, Burse VW, Patterson DG Jr, Sampson EJ, et al. Relation of a seafood diet to mercury, selenium, arsenic, and polychlorinated biphenyl and other organochlorine concentrations in human milk. Environ Res. 1995; 71:29-38. [PubMed: 8757236]

22. Needham LL, Grandjean P, Heinzow B, Jorgensen PJ, Nielsen F, Patterson DG Jr, et al. Partition of environmental chemicals between maternal and fetal blood and tissues. Environ Sci Technol. 2011; 45:1121-6. [PubMed: 21166449]

23. Andersson AM, Juul A, Petersen JH, Muller J, Groome NP, Skakkebaek NE. Serum inhibin B in healthy pubertal and adolescent boys: relation to age, stage of puberty, and follicle-stimulating hormone, luteinizing hormone, testosterone, and estradiol levels. J Clin Endocrinol Metab. 1997; 82:3976-81. [PubMed: 9398699]

24. Aksglaede L, Sorensen K, Petersen JH, Skakkebaek NE, Juul A. Recent decline in age at breast development: the Copenhagen Puberty Study. Pediatrics. 2009; 123:e932-9. [PubMed: 19403485]

25. Hastie, TJ.; Tibshirani, RJ. Generalized Additive Models (Monographs on Statistics and Applied Probability 43). Boca Raton, FL: Chapman and Hall/CRC Press; 1990.

26. Bollen, KA. Structural equations with latent variables. New York: John Wiley; 1989.

27. Skrondal, A.; Rabe-Hesketh, S. Generalized latent variable modeling: multilevel, longitudinal, and structural equation models. Boca Raton: Chapman \& Hall/CRC; 2004.

28. Budtz-Jorgensen E, Debes F, Weihe P, Grandjean P. Structural equation models for meta-analysis in environmental risk assessment. Environmetrics. 2010; 21:510-27. [PubMed: 20890403]

29. Debes F, Budtz-Jorgensen E, Weihe P, White RF, Grandjean P. Impact of prenatal methylmercury exposure on neurobehavioral function at age 14 years. Neurotoxicology and teratology. 2006; 28:536-47. [PubMed: 17067778]

30. Budtz-Jorgensen E, Keiding N, Grandjean P, Weihe P. Estimation of health effects of prenatal methylmercury exposure using structural equation models. Environ Health. 2002; 1:2. [PubMed: 12513702]

31. Mocarelli P, Gerthoux PM, Needham LL, Patterson DG Jr, Limonta G, Falbo R, et al. Perinatal exposure to low doses of dioxin can permanently impair human semen quality. Environmental health perspectives. 2011; 119:713-8. [PubMed: 21262597]

32. Sorensen K, Aksglaede L, Petersen JH, Juul A. Recent changes in pubertal timing in healthy Danish boys: associations with body mass index. J Clin Endocrinol Metab. 2010; 95:263-70. [PubMed: 19926714]

33. Sorensen K, Aksglaede L, Munch-Andersen T, Aachmann-Andersen NJ, Petersen JH, Hilsted L, et al. Sex hormone-binding globulin levels predict insulin sensitivity, disposition index, and cardiovascular risk during puberty. Diabetes Care. 2009; 32:909-14. [PubMed: 19196890]

34. Turyk ME, Anderson HA, Freels S, Chatterton R Jr, Needham LL, Patterson DG Jr, et al. Associations of organochlorines with endogenous hormones in male Great Lakes fish consumers and nonconsumers. Environmental research. 2006; 102:299-307. [PubMed: 16563369]

35. Haugen TB, Tefre T, Malm G, Jonsson BA, Rylander L, Hagmar L, et al. Differences in serum levels of CB-153 and p,p'-DDE, and reproductive parameters between men living south and north in Norway. Reproductive toxicology. 2011; 32:261-7. [PubMed: 21736938]

36. European Food Safety Authority. Opinion of the scientific panel on contaminants in the food chain on a request from the Commission related to the presence of non-dioxin-like polychlorinated biphenyls (PCB) in feed and food. The EFSA Journal. 2005; 284:1-137.

37. Longnecker MP, Wolff MS, Gladen BC, Brock JW, Grandjean P, Jacobson JL, et al. Comparison of polychlorinated biphenyl levels across studies of human neurodevelopment. Environmental health perspectives. 2003; 111:65-70. [PubMed: 12515680]

38. Gladen BC, Ragan NB, Rogan WJ. Pubertal growth and development and prenatal and lactational exposure to polychlorinated biphenyls and dichlorodiphenyl dichloroethene. J Pediatr. 2000; 136:490-6. [PubMed: 10753247]

39. Guo YL, Lambert GH, Hsu CC, Hsu MM. Yucheng: health effects of prenatal exposure to polychlorinated biphenyls and dibenzofurans. Int Arch Occup Environ Health. 2004; 77:153-8. [PubMed: 14963712] 
40. Tait S, La Rocca C, Mantovani A. Exposure of human fetal penile cells to different PCB mixtures: transcriptome analysis points to diverse modes of interference on external genitalia programming. Reprod Toxicol. 2011; 32:1-14. [PubMed: 21334430]

41. Steinberg RM, Walker DM, Juenger TE, Woller MJ, Gore AC. Effects of perinatal polychlorinated biphenyls on adult female rat reproduction: development, reproductive physiology, and second generational effects. Biol Reprod. 2008; 78:1091-101. [PubMed: 18305224]

42. Kraugerud M, Aleksandersen M, Nyengaard JR, Ostby GC, Gutleb AC, Dahl E, et al. In utero and lactational exposure to PCB 118 and PCB 153 alter ovarian follicular dynamics and GnRHinduced luteinizing hormone secretion in female lambs. Environ Toxicol. 2011 


\section{highlights}

- Cinical aspects of puberty development in boys prenatally exposed to environmental chemicals

- PCB exposure in the cohort population due to the traditional consumption of whale blubber 

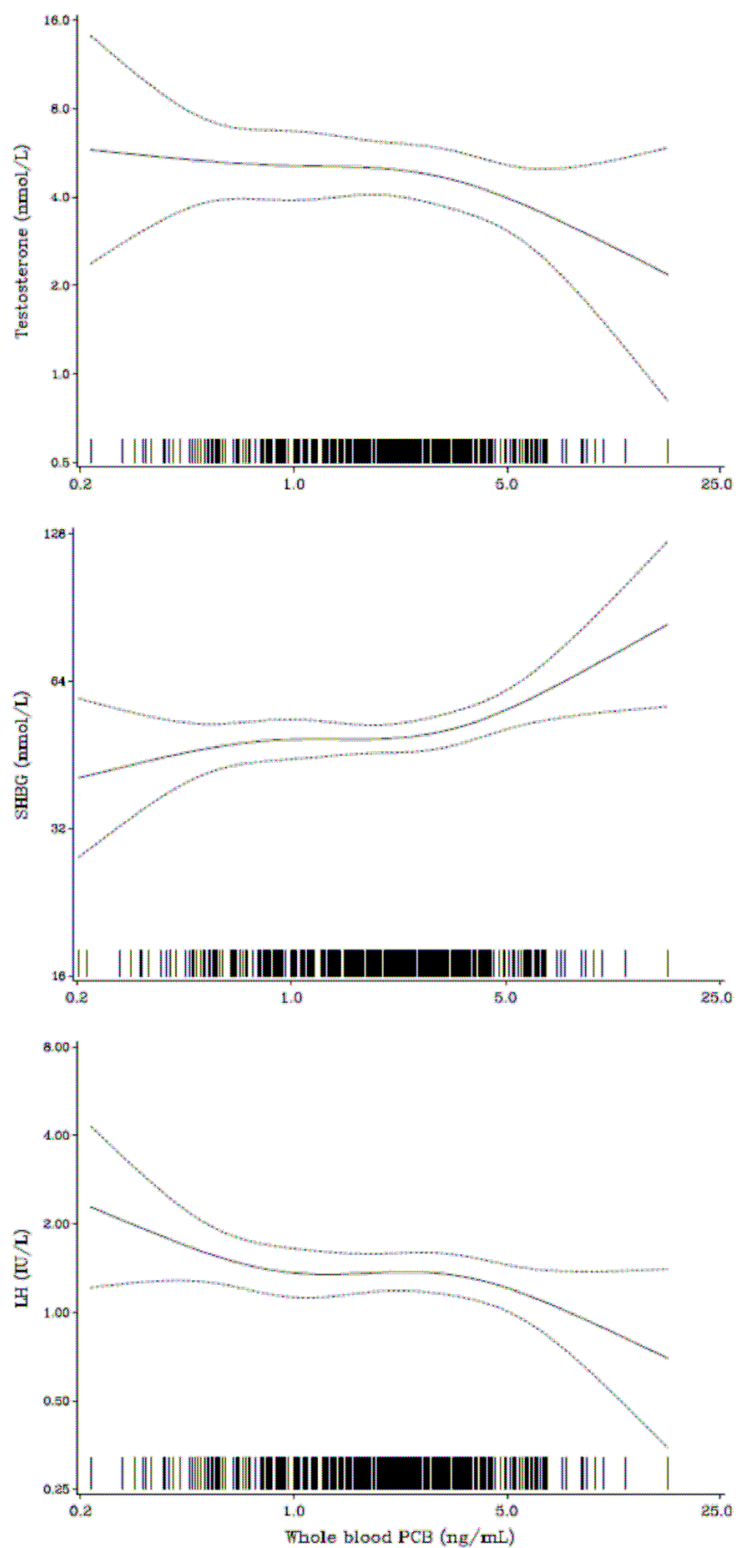

Fig. 1.

Generalized additive models for the covariate-adjusted cord-blood PCB concentration as a predictor of serum-hormone concentrations in 451 boys at age 14 years. 


\section{Table 1}

Main characteristics of boys from a Faroese birth cohort who participated in clinical examinations at age 14 years.

\begin{tabular}{|c|c|c|}
\hline & Number & Mean \pm SD \\
\hline Age at examination (years) & 438 & $13.82 \pm 0.31$ \\
\hline BMI $\left(\mathrm{kg} / \mathrm{m}^{2}\right)$ & 438 & $20.26 \pm 3.80$ \\
\hline \multicolumn{3}{|l|}{ Mean testicular size $(\mathrm{mL})^{*}$} \\
\hline Orchidometer & 327 & $9.4 \pm 4.5$ \\
\hline Ultrasound & 107 & $7.2 \pm 3.6$ \\
\hline Combined $^{* *}$ & 374 & $9.4 \pm 4.4$ \\
\hline Time of blood sample (noon/5 pm) (number) & 438 & $233 / 205$ \\
\hline \multicolumn{3}{|l|}{ Tanner stage (number) } \\
\hline Pubic hair $(2 / 3 / 4 / 5)$ & 394 & $129 / 115 / 140 / 10$ \\
\hline Genital development $(2 / 3 / 4 / 5)$ & 394 & $87 / 136 / 159 / 12$ \\
\hline Cord blood-PCB $(\mathrm{ng} / \mathrm{mL})^{* * *}$ & 433 & $1.93(1.16-3.16)$ \\
\hline Cord blood-DDE (ng/mL) ${ }^{* * *}$ & 433 & $0.88(0.49-1.57)$ \\
\hline Age-14 serum-PCB $(\mu \mathrm{g} / \mathrm{g}$ lipid $) * * *$ & 405 & $0.85(0.49-1.56)$ \\
\hline Age-14 serum-DDE $(\mu \mathrm{g} / \mathrm{g}$ lipid $){ }^{* * *}$ & 404 & $0.56(0.29-1.14)$ \\
\hline \multicolumn{3}{|l|}{ Subjects with history of cryptorchidism excluded } \\
\hline \multicolumn{3}{|c|}{ *** Missing orchidometer measures were substituted by adjusted ultrasound measures } \\
\hline
\end{tabular}




\section{Table 2}

Serum hormone concentrations and other pubertal development parameters (mean \pm SD) in Faroese boys at 14 years of age in tertile groups of PCB concentrations in umbilical cord blood $(\mathrm{ng} / \mathrm{mL})$.

\begin{tabular}{|c|c|c|c|}
\hline & Low $(N=144)$ & Intermediate $(N=143)$ & $\operatorname{High}(N=146)$ \\
\hline Age (years) & $13.8 \pm 0.3$ & $13.8 \pm 0.3$ & $13.8 \pm 0.3$ \\
\hline Height (cm) & $164.4 \pm 8.2$ & $163.9 \pm 8.0$ & $163.9 \pm 8.6$ \\
\hline Weight (kg) & $54.3 \pm 11.0$ & $54.1 \pm 11.1$ & $53.8 \pm 11.9$ \\
\hline BMI $\left(\mathrm{kg} / \mathrm{m}^{2}\right)$ & $20.0 \pm 3.4$ & $20.0 \pm 3.3$ & $19.9 \pm 3.3$ \\
\hline Testicular size $(\mathrm{mL})^{* *}$ & $9.9 \pm 4.4$ & 9.44 .7 & $9.1 \pm 4.4$ \\
\hline Tanner stage (pubic) ${ }^{*}$ & $3.19 \pm 0.90$ & $3.09 \pm 0.90$ & $2.95 \pm 0.84$ \\
\hline Tanner stage (genital) & $3.32 \pm 0.85$ & $3.28 \pm 0.82$ & $3.14 \pm 0.82$ \\
\hline $\mathrm{LH}(\mathrm{IU} / \mathrm{L}) \xi^{*}$ & $1.40(0.77-2.54)$ & $1.32(0.79-2.34)$ & $1.16(0.64-2.28)$ \\
\hline $\mathrm{FSH}(\mathrm{IU} / \mathrm{L}) \mathcal{\xi}$ & $2.38(1.59-3.40)$ & $2.41(1.54-3.40)$ & $2.21(1.49-3.27)$ \\
\hline Inhibin B (pg/mL) & $177 \pm 66$ & $168 \pm 67$ & $178 \pm 68$ \\
\hline $\mathrm{T}(\mathrm{nmol} / \mathrm{L}) \mathcal{\xi}$ & $3.51(1.70-9.98)$ & $3.35(1.59-10.38)$ & $2.48(1.21-9.12)$ \\
\hline $\mathrm{SHBG}(\mathrm{nmol} / \mathrm{L}) \xi^{*}$ & $47(34-68)$ & $50(37-69)$ & $54(38-73)$ \\
\hline $\mathrm{T} / \mathrm{SHBG}$ ratio & $0.073(0.027-0.26)$ & $0.067(0.025-0.24)$ & $0.047(0.021-0.21)$ \\
\hline \multicolumn{4}{|c|}{$\mathrm{p}<0.05$ for trend; in addition, $0.05<\mathrm{p}<0.10$ for $\mathrm{LH}$, SHBG, and genital Tanner stage } \\
\hline \multicolumn{4}{|c|}{$\xi_{\text {Geometric mean with interquartile range in parenthesis }}$} \\
\hline
\end{tabular}




\section{Table 3}

Regression coefficients ( $p$ values) for the cord blood PCB concentration as predictor for serum concentrations of LH, T, and SHBG before and after adjustment for age, BMI, history of cryptorchidism and time of blood sampling. In addition, the joint effect on the three hormone parameters has been assessed in a structural equation model. All parameters are log transformed.

\begin{tabular}{lcc}
\hline & Unadjusted & Adjusted $^{+}$ \\
\hline LH (IU/L) & $-0.119(0.037)$ & $-0.134(0.023)$ \\
T (IU/L) & $-0.133(0.117)$ & $-0.154(0.069)$ \\
SHBG (nmol/mL) & $0.090(0.008)$ & $0.092(0.003)$ \\
T/SHBG ratio & $-0.223(0.033)$ & $-0.245(0.016)$ \\
& - & $-0.088(0.030)$ \\
\hline
\end{tabular}

Expressed in terms of $\mathrm{LH}$, as determined by structural equation model

${ }^{+}$Covariates were age, BMI, and time of blood sampling 